\title{
THE ABILITY OF OXIME MIXTURES TO INCREASE THE REACTIVATING AND THERAPEUTIC EFFICACY OF ANTIDOTAL TREATMENT OF CYCLOSARIN POISONING IN RATS AND MICE
}

\author{
Jiř̌i Kassa ${ }^{1}$, Jana Zdarová Karasová ${ }^{2}$ Růžena Pavlíková ${ }^{1}$, Filip Caisberger ${ }^{1,3}$, Jiří Bajgar ${ }^{1}$
}

\begin{abstract}
University of Defence, Faculty of Military Health Sciences, Hradec Králové, Czech Republic: Department of Toxicology; Department of Public Health ${ }^{2}$; Charles University in Prague, Faculty of Medicine and University Hospital in Hradec Králové, Czech Republic: Department of Anatomy ${ }^{3}$
\end{abstract}

Summary: The reactivating and therapeutic efficacy of two combinations of oximes (HI-6 + trimedoxime and HI-6 + K203) was compared with the effectiveness of antidotal treatment involving single oxime (HI-6, trimedoxime, K203) using in vivo methods. In vivo determined percentage of reactivation of cyclosarin-inhibited blood and tissue acetylcholinesterase in poisoned rats showed that the reactivating efficacy of both combinations of oximes is slightly higher than the reactivating efficacy of the most effective individual oxime in blood, diaphragm as well as in brain. Moreover, both combinations of oximes were found to be slightly more efficacious in the reduction of acute lethal toxic effects in cyclosarin-poisoned mice than the antidotal treatment involving single oxime. Based on the obtained data, we can conclude that the antidotal treatment involving chosen combinations of oximes brings a beneficial effect for its ability to counteract the acute poisoning with cyclosarin.

Keywords: Acetylcholinesterase; Cyclosarin, HI-6; Trimedoxime; K203; Mice; Rats

\section{Introduction}

Classic nerve agents, such as tabun, sarin, soman, cyclosarin, and VX, are highly toxic organophosphorus compounds that present a serious threat to both military and civilian populations. They exert their biological effects by the inhibition of the enzyme acetylcholinesterase (AChE, EC 3.1.1.7) found at the receptor sites of tissue innervated by the cholinergic nervous system, which hydrolyzes the neuromediator acetycholine (ACh). The inhibition of AChE increases the amount of $\mathrm{ACh}$ at central and peripheral sites of the nervous system and causes the overstimulation of postsynaptic cholinergic receptors. Left untreated, nerve agent poisoning may result in a rapid progression of symptoms and signs including hypersecretion, convulsions and possibly death due to respiratory failure $(1,24)$.

Current medical protection against the toxicity of nerve agents consists of anticholinergic drugs, such as atropine, to counteract the accumulation of ACh and nucleophiles such as pyridinium oximes to reactivate nerve agent-inhibited AChE. The oxime-induced reactivation is the primary therapeutic approach to nerve agent poisoning (11). Till now, some oximes (pralidoxime, obidoxime, trimedoxime, HI-6) were developed and fielded to be used in the antidotal treatment of nerve agent poisonings, however, their reactivating efficacy is rather limited $(5,11)$. While most of reactivators are sufficiently effective to reactivate sarin or VX-inhibited
AChE, their potency to reactivate soman, cyclosarin or tabun-inhibited AChE is generally low $(1,11)$.

The threat of misuse of different nerve agents in wartime or by terrorists $(22,33)$ raised the need of the development of oximes with the ability to counteract acute toxicity of all nerve agents. Recently, a lot of oximes were developed and evaluated $(8,21,23,31,32)$, however, none of them was considered to be able to satisfactorily reactivate AChE inhibited with all nerve agents $(2,13,26,28,29)$. Therefore, the replacement of commonly used oximes with sufficiently effective, broad-spectrum oximes has been a long-standing goal for the treatment of nerve agent poisonings.

A possible approach how to broaden the spectrum of oximes to obtain sufficiently effective antidotes against all nerve agents regardless of their chemical structure is to combine chosen oximes to cover the whole spectrum of nerve agents. In this study, the combination of HI- 6 with trimedoxime or recently developed oxime K203 was used (Figure 1). Both combinations of oximes were considered to be suitable for the antidotal treatment of acute tabun and soman poisonings $(14,15)$ but it is necessary to know if these combinations of oximes are also sufficiently effective against all other nerve agents.

The reactivating and therapeutic efficacy of both mixtures of oximes in combination with atropine was evaluated against cyclosarin (cyclohexyl methylphosphonofluoridate) to find how the combination of the oxime HI- 6 with another 


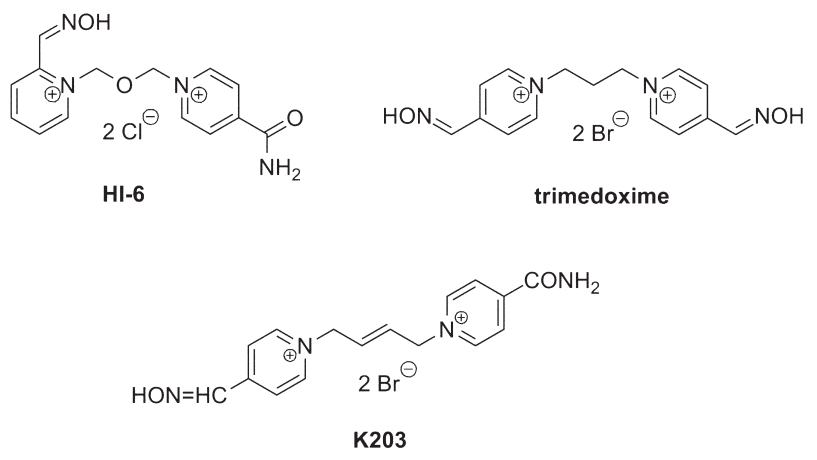

Fig. 1: Chemical structure of oximes

oxime (trimedoxime, K203) can influence the reactivating and therapeutic effectiveness of antidotal treatment of acute cyclosarin poisoning. The potency of chosen oxime mixtures to reactivate cyclosarin-inhibited $\mathrm{AChE}$ in rats and reduce acute toxicity of cyclosarin in mice was compared with the reactivating and therapeutic efficacy of three individual oximes (trimedoxime, the oxime HI-6, the oxime K203).

\section{Material and Methods}

Male albino Wistar rats weighing 190-230 $\mathrm{g}$ and NMRI male mice weighing between 18 and $22 \mathrm{~g}$ were purchased from VELAZ (Prague, Czech Republic). They were kept in an air-conditioned room with the light from 07:00 to 19:00 $\mathrm{hr}$ and were allowed access to standard food and tap water $a d$ libitum. The rats were divided into groups of 8 animals. The procedures followed were in accordance with the standards set forth in the Guide for the Care and Use of Laboratory Animals. Handling of the experimental animals was done under the supervision of the Ethics Committee of the Faculty of Military Health Sciences, Czech Republic.

Cyclosarin of $96 \%$ purity was purchased from the Technical Institute in Brno (Czech Republic). Its purity was assayed by acidimetric titration. Trimedoxime, the oxime HI-6 and the oxime K203 of 98\% purity were synthesized at the Department of Toxicology of the Faculty of Military Health Sciences (Czech Republic). Their purity was analyzed using a HPLC technique (10). All other drugs and chemicals of analytical grade were obtained commercially and used without further purification. All substances were administered intramuscularly (i.m.) at a volume of $1 \mathrm{~mL} / \mathrm{kg}$ body weight (b.w.) in rats and $10 \mathrm{~mL} / \mathrm{kg}$ b.w. in mice.

To evaluate the reactivating efficacy of the oximes, the rats were administered i.m. with either atropine sulfate monohydrate $(21 \mathrm{mg} / \mathrm{kg})$ alone or atropine sulfate monohydrate $(21 \mathrm{mg} / \mathrm{kg})$ in combination with one of studied oximes (trimedoxime, HI-6, K203) or with the mixture of HI-6 with trimedoxime or $\mathrm{K} 203$ in equitoxic doses $\left(5 \% \mathrm{LD}_{50}\right)(15)$. They were administered at $1 \mathrm{~min}$ after the rats received cyclosarin i.m. at a dose of $160 \mu \mathrm{g} / \mathrm{kg}\left(\mathrm{LD}_{50}\right)$. The rats were decapitated and exsanguinated to obtain the blood $60 \mathrm{~min}$ subsequent to cyclosarin poisoning. The blood was hemolyzed in Tris- $\mathrm{HCl}$ buffer $(0.02 \mathrm{~mol} / \mathrm{l}, \mathrm{pH} 7.6,1: 20)$. The tissues, diaphragm and brain were removed and homogenized by the homogenizator Ultra-Turrax T25 Basic in Tris-HCl buffer $(0.02 \mathrm{~mol} / \mathrm{l}$, $\mathrm{pH} 7.6,1: 10)$ to determine AChE activity by standard spectrophotometric method (6). Helios Alpha spectrophotometer was used for the determination of absorbance at $436 \mathrm{~nm}$. The AChE activity was expressed as $\mu \mathrm{kat} / \mathrm{kg}$ or $\mathrm{L}(\mu \mathrm{mol}$ substrate hydrolyzed/kg tissue or L blood within 1 second). The values of control group for blood, diaphragm and brain AChE activity were obtained from rats administered with saline buffer instead of cyclosarin and antidotes (saline control). The percentage of reactivation was calculated using the $\mathrm{AChE}$ activity values: $\{1-[(($ saline control $)-($ oxime + atropine $)) /$ $(($ saline control) $-($ atropine control) $)]\} \times 100$ (equation modified from Clement -3$)$.

The therapeutic efficacy of oximes (single oxime or mixture of oximes) in combination with atropine against cyclosarin in mice was determined as follows. The $\mathrm{LD}_{50}$ value of cyclosarin and its $95 \%$ confidence limit was assessed using probit-logarithmical analysis of death occuring within $24 \mathrm{~h}$ after i.m. administration of cyclosarin at five different doses with eight mice per dose (35). Then, cyclosarin-poisoned mice were treated i.m. with one of tested oximes or with the mixture of oximes at equitoxic doses $\left(5 \% \mathrm{LD}_{50}\right)$ in combination with atropine sulfate monohydrate $(21 \mathrm{mg} / \mathrm{kg})$ at $1 \mathrm{~min}$ after i.m. administration of cyclosarin to assess $\mathrm{LD}_{50}$ values of cyclosarin and their $95 \%$ confidence limits. The ability of tested antidotal mixtures to reduce acute toxicity of cyclosarin was expressed as protective ratio $\left(\mathrm{LD}_{50}\right.$ value of cyclosarin in protected mice/ $/ \mathrm{LD}_{50}$ value of cyclosarin in unprotected mice). Statistical significance was determined by the use of one-way ANOVA test and differences were considered significant when $\mathrm{P}<0.05$ (35).

\section{Results}

The ability of oximes to reactivate cyclosarin-inhibited $\mathrm{AChE}$ in rat blood, diaphragm and brain in vivo is shown in Table 1. The oxime HI-6 seems to be the most effective reactivator of cyclosarin-inhibited $\mathrm{AChE}$ in the peripheral as well as central compartment. It was able to increase the activity of cyclosarin-inhibited AChE in blood by more than $90 \%$, in diaphragm by more than $70 \%$ and in brain by more than $60 \%$. The differences between HI- 6 and other studied oximes (trimedoxime, K203) in blood, diaphragm as well as brain were significant $(\mathrm{P}<0.05)$. Trimedoxime and the oxime K203 were slightly effective reactivators of cyclosarin-inhibited $\mathrm{AChE}$ in blood and diaphragm but they were ineffective in reactivating of cyclosarin-inhibited $\mathrm{AChE}$ in brain. The differences in reactivating efficacy of trimedoxime and K203 were not significant. When the combination of HI-6 with trimedoxime or K203 was used, the reactivating efficacy of antidotal treatment was slightly higher than the reactivating efficacy of the most effective 
Tab. 1: Percentage of reactivation of cyclosarin-inhibited AChE by oximes in rat blood, diaphragm and brain in vivo

\begin{tabular}{|c|c|c|c|}
\hline \multirow[t]{2}{*}{ TREATMENT } & \multicolumn{3}{|c|}{ AChE activity ( $\mu$ kat/L or $\mu \mathrm{kat} / \mathrm{kg}$ ) } \\
\hline & Blood & Diaphragm & Brain \\
\hline Atropine & $5.52 \pm 0.99^{\mathrm{a}}$ & $8.79 \pm 1.54^{\mathrm{a}}$ & $30.42 \pm 3.02^{\mathrm{a}}$ \\
\hline $\begin{array}{l}\text { Atropine }+ \text { trimedoxime } \\
\left(\% \text { reactivation }^{b}\right)\end{array}$ & $\begin{array}{c}7.74 \pm 1.53 \\
(8.8)\end{array}$ & $\begin{array}{l}10.34 \pm 1.11 \\
(12.9)\end{array}$ & $\begin{array}{c}29.90 \pm 2.05 \\
(0)\end{array}$ \\
\hline $\begin{array}{l}\text { Atropine }+ \text { HI-6 } \\
(\% \text { reactivation })\end{array}$ & $\begin{array}{c}19.60 \pm 1.56 \\
\left(94.6^{* x}\right)\end{array}$ & $\begin{array}{c}17.27 \pm 2.84 \\
\left(70.4^{* x}\right)\end{array}$ & $\begin{array}{c}100.80 \pm 14.30 \\
\left(63.2^{* x}\right)\end{array}$ \\
\hline $\begin{array}{l}\text { Atropine }+\mathbf{K 2 0 3} \\
(\% \text { reactivation })\end{array}$ & $\begin{array}{c}8.78 \pm 0.77 \\
\left(16.3^{*}\right)\end{array}$ & $\begin{array}{l}10.38 \pm 2.04 \\
(13.2)\end{array}$ & $\begin{array}{c}30.34 \pm 5.49 \\
(0)\end{array}$ \\
\hline $\begin{array}{l}\text { Atropine }+ \text { trimedoxime }+ \text { HI-6 } \\
(\% \text { reactivation })\end{array}$ & $\begin{array}{l}19.56 \pm 2.30 \\
\left(94.4^{* x}\right)\end{array}$ & $\begin{array}{l}17.54 \pm 2.73 \\
\left(72.6^{* x}\right)\end{array}$ & $\begin{array}{l}105.00 \pm 7.01 \\
\left(67.0^{* x}\right)\end{array}$ \\
\hline $\begin{array}{l}\text { Atropine }+ \text { HI-6 }+ \text { K203 } \\
(\% \text { reactivation })\end{array}$ & $\begin{array}{c}19.97 \pm 1.39 \\
\left(97.3^{* x}\right)\end{array}$ & $\begin{array}{l}18.30 \pm 2.62 \\
\left(78.9^{*} x\right)\end{array}$ & $\begin{array}{l}103.60 \pm 27.2 \\
\left(65.6^{* x}\right)\end{array}$ \\
\hline
\end{tabular}

${ }^{a}$ Means \pm S.E.M., $\mathrm{N}=8$. The untreated control value for rat blood AChE activity was $20.34 \pm 2.47 \mu \mathrm{kat} / \mathrm{L}$, for diaphragm AChE activity $20.84 \pm 3.95 \mu \mathrm{kat} / \mathrm{kg}$ and for brain AChE activity $141.7 \pm 9.36 \mu \mathrm{kat} / \mathrm{kg}$.

${ }^{\mathrm{b}}$ Percent reactivation was determined using the AChE activity values: $\{1-[(($ saline $)-($ oxime + atropine $)) /(($ saline $)-($ atropine control)) $]\} \times 100$.

${ }^{*}$ Significantly different from the atropine group at a level of $\mathrm{P}<0.05,{ }^{\mathrm{x}}$ significantly different from the atropine + trimedoxime (K203) group at a level of $\mathrm{P}<0.05$ as determined by one-way ANOVA test.

Tab. 2: The influence of the type of oxime on the ability of antidotal treatment to reduce acute lethal effects of cyclosarin in mice

\begin{tabular}{|c|c|c|}
\hline Treatment & $\mathrm{LD}_{50}(\mu \mathrm{g} / \mathrm{kg}) \pm 95 \% \mathrm{IS}$ & Protective ratio \\
\hline Without treatment & $181.7(143.4-212.7)$ & - \\
\hline Trimedoxime + atropine & $223.7(204.5-241.0)$ & 1.23 \\
\hline HI- $6+$ atropine & $400.0(337.2-474.5)^{* x}$ & 2.20 \\
\hline K203 + atropine & $197.6(149.4-261.4)$ & 1.09 \\
\hline HI-6 + trimedoxime + atropine & $436.5(381.3-533.5)^{* x}$ & 2.40 \\
\hline HI-6 + K203 + atropine & $474.4(401.7-560.3)^{* x}$ & 2.61 \\
\hline
\end{tabular}

* Significantly different from the untreated group at a level of $\mathrm{P}<0.05$, ${ }^{\mathrm{x}}$ significantly different from the group treated by atropine in combination with trimedoxime or K203 at a level of $\mathrm{P}<0.05$.

single oxime (HI-6) in blood, diaphragm as well as in brain although the difference among them was not significant.

The therapeutic efficacy of studied oximes and their combinations against lethal cyclosarin poisoning in mice is shown in Table 2. Various clinical muscarinic and nicotinic signs and symptoms were observed in mice shortly after i.m. administration of cyclosarin. They died within 30 minutes after poisoning with cyclosarin. The ability of trimedoxime and the oxime K203 to reduce the acute toxicity of cyclosarin was relatively low. They were able to decrease the acute toxicity of cyclosarin less than 1.3 fold. On the other hand, the oxime HI-6 showed significantly higher potency to reduce acute lethal toxic effects of cyclosarin in mice than trimedoxime and K203. It decreased the acute toxicity of cyclosarin more than two times. In the case of antidotal treatment of cyclosarin-poisoned mice with atropine and combination of HI- 6 with trimedoxime or K203, the therapeutic efficacy of antidotes was slightly higher than the therapeutic efficacy of the oxime HI-6 alone.

\section{Discussion}

Generally, currently used as well as newly developed monopyridinium and bispyridinium oximes are not able to sufficiently reactivate AChE inhibited by all nerve agents regardless of their chemical structure $(31,34)$. Another possible approach how to reach the satisfactorily effective antidotal tretment of acute poisonings with nerve agents regardless of their chemical structure is to combine two oximes with different spectrum of their reactivating and therapeutic efficacy $(4,16,17,27)$. The oxime HI-6 appears to be the most promising antidote against nerve agents, especially soman and cyclosarin $(7,20,25,26)$. However, its potency to counteract the acute toxicity of tabun is rather low (11, 25 ). Therefore, the second oxime involved into the antidotal treatment of nerve agent poisonings should be satisfactorily effective against tabun. Among currently available oximes, trimedoxime is considered to be the most effective against tabun $(9,18,31)$. In addition, a novel oxime K203 was 
recently evaluated to be relatively effective reactivator of tabun-inhibited AChE by in vitro as well as in vivo experiments $(12,19,30)$.

When the potency of the combination of two oximes (HI-6 and obidoxime) to reactivate $\mathrm{AChE}$ inhibited by nerve agents (sarin, cyclosarin, VX, tabun) was evaluated in vitro, no negative effects on the reactivation of sarin-, cyclosarin-, VX- and tabun-inhibited human AChE was observed (36). The results published by Worek and his co-workers (36) correspond to in vivo data. The beneficial effects of various combinations of oximes on the reactivating and therapeutic efficacy of antidotal treatment of acute poisonings with various nerve agents were demonstrated several times in the literature $(4,16,17,27)$.

These literature data are in agreement with our in vivo results. They clearly demonstrate that a combination of HI-6 with trimedoxime or $\mathrm{K} 203$ is more effective than single oxime treatment related to the reactivation of cyclosarin-inhibited $\mathrm{AChE}$ in blood, diaphragm and brain in rats and to the reduction of acute toxicity of cyclosarin in mice although the difference between oxime mixtures studied and the most effective single oxime (HI-6) is not so high. The beneficial effects of both studied combinations of oximes compared to individual oxime treatment could be explained by an elevated plasma oxime level and synergetic effects of both oximes (36).

Thus, the antidotal treatment involving a combination of two oximes and atropine represents not only promising treatment of acute poisoning with tabun (15) but also with cyclosarin. On the other hand, the beneficial effect of oxime mixtures for the antidotal treatment of acute poisoning with soman was not found, probably due to the rapid aging of soman-inhibited AChE (14). Based on the above mentioned results, we can conclude that the combination of two oximes seems to be the suitable approach how to broaden the effectiveness of antidotal treatment of poisonings with nerve agents regardless of their chemical structure.

\section{Acknowledgements}

The authors wish to thank to Mrs Jana Uhlirova for her skilful assistance and Dr. Blaha for the statistical evaluation of data. The study was supported by the grant of Ministry of Defense "A long term organization development plan 2011".

\section{References}

1. Bajgar J. Organophosphate/nerve agent poisoning: mechanism of action, diagnosis, prophylaxis and treatment. Adv Clin Chem 2004; 38: 151-216.

2. Bajgar J. Complex view on poisoning with nerve agents and organophosphates. Acta Med (Hradec Kralove) 2005; 48: 3-21.

3. Clement JG, Hansen AS, Boulet CA. Efficacy of HLö-7 and pyrimidoxime as antidotes of nerve agent poisoning in mice. Arch Toxicol 1992; 66: 216-9.

4. Clement JG, Shiloff JD, Gennings Ch. Efficacy of a combination of acetylcholinesterase reactivators, $\mathrm{HI}-6$ and obidoxime, against tabun and soman poisoning of mice. Arch Toxicol 1987; 61: 70-5.

5. Dawson RM. Review of oximes available for treatment of nerve agent poisoning. J Appl Toxicol 1994; 14: 317-31.

6. Ellman GL, Courtney DK, Andres VJr, Feartherstone RM. A new and rapid colorimetric determination of acetylcholinesterase activity. Biochem Pharmacol 1961; 7: $88-93$.

7. Herkert NM, Lallement G, Clarencon D, Thiermann H, Worek F. Comparison of the oxime-induced reactivation of rhesus monkey, swine and guinea pig erythrocyte acetylcholinesterase following inhibition by sarin or paraoxon, using a perfusion model for the real-time determination of membrane-bound acetylcholinesterase activity. Toxicology 2009; 258: 79-83.

8. Jeong $\mathrm{HCH}$, Park NJ, Chae $\mathrm{CHH}$ et al. Fluorinated pyridinium oximes as potential reactivators for acetylcholinesterases inhibited by paraoxon organophosphorus agent. Bioorg Med Chem 2009; 17: 6213-7.

9. Jokanovic M, Prostran M. Pyridinium oximes as cholinesterase reactivators. Structure-activity relationship and efficacy in the treatment of poisoning with organophosphorus compounds. Curr Med Chem 2009; 16: 2177-88.

10. Jun D, Kuca K, Stodulka P et al. HPLC analysis of HI-6 dichloride and dimethansulfonate - antidotes against nerve agents and organophosphorus pesticides. Anal Lett 2007; 40: 2783-7.

11. Kassa J. Review of oximes in the antidotal treatment of poisoning by organophosphorus nerve agents. J Toxicol Clin Toxicol 2002; 40: 803-16.

12. Kassa J, Karasova J, Musilek K, Kuca K. An evaluation of therapeutic and reactivating effects of newly developed oximes (K156, K203) and commonly used oximes (obidoxime, trimedoxime, HI-6) in tabun-poisoned rats and mice. Toxicology $2008 ; 243: 311-6$.

13. Kassa J, Kuca K, Bartosova L, Kunesova G. The development of new structural analogues of oximes for the antidotal treatment of poisoning by nerve agents and the comparison of their reactivating and therapeutic efficacy with currently available oximes. Curr Org Chem 2007; 11:267-83.

14. Kassa J, Zdarova Karasova J, Caisberger F, Bajgar J. The influence of combinations of oximes on the reactivating and therapeutic efficacy of antidotal treatment of soman poisoning in rats and mice. Toxicol Mech Method 2009; 19: 547-51.

15. Kassa J, Zdarova Karasova J, Pavlikova R, Misik J, Caisberger F, Bajgar J. The influence of combinations of oximes on the reactivating and therapeutic efficacy of antidotal treatment of tabun poisoning in rats and mice. J Appl Toxicol 2010; 30: $120-4$.

16. Kovacevic V, Maksimovic M, Deljac V, Binenfeld Z. Protective effects of mixture of oximes in poisoning by nerve chemical warfare agents. Acta Pharm Jugoslav 1991; 41: 75-8.

17. Kovacevic V, Maksimovic M, Pantelic D, Vojvodic V, Binenfeld Z. Protective and reactivating effects of HI-6 + PAM-2 mixture in rats poisoned with nerve chemical warfare agents. Acta Pharm Jugoslav 1989; 39: 161-5.

18. Kovarik Z, Calic M, Sinko G et al. Oximes: Reactivators of phosphorylated acetylcholinesterase and antidotes in therapy against tabun poisoning. Chem Biol Interact 2008; 175: 173-9.

19. Kovarik Z, Lucic Vrdoljak A, Berend S et al. Evaluation of oxime K203 as antidote in tabun poisoning. Arh Hig Rada Toksikol 2009; 60: 19-26.

20. Kuca K, Musilek K, Jun D et al. Could oxime HI-6 really be considered as "broad-spectrum" antidote? J Appl Biomed 2009; 7: 143-9.

21. Kuca K, Picha J, Cabal J, Liska F. Synthesis of the three monopyridinium oximes and evaluation of their potency to reactivate acetylcholinesterase inhibited by nerve agents. J Appl Biomed 2004; 2: 51-6.

22. Lawrence DT, Kirk MA. Chemical terrorism attacks: update on antidotes. Emerg Med Clin N Am 2007; 25: 567-95.

23. Lorke DE, Hasan MY, Nurulain SM, Kuca K, Schmitt A, Petroianu GA. Efficacy of two asymmetric bispyridinium oximes (K-27 and K-48) in rats exposed to diisopropylfluorophosphate: comparison with pralidoxime, obidoxime, trimedoxime, methoxime, and HI-6. Toxicol Mech Method 2009; 19: 327-33.

24. Lotti M. Organophosphorus compounds. In: Spencer PS, Schaumburg HH, eds Experimental and Clinical Neurotoxicology. New York: Oxford University Press, 2000: 898-925.

25. Lundy PM, Raveh L, Amitai G. Development of the bisquaternary oxime HI-6 toward clinical use in the treatment of organophosphate nerve agent poisoning. Toxicol Rev 2006; 25: 231-43.

26. Luo CY, Tong M, Chilukuri N, Brecht K, Maxwell DM, Saxena A. An in vitro comparative study on the reactivation of nerve agent-inhibited guinea-pig and human acetylcholinesterases by oximes. Biochemistry 2007; 48: 11771-9.

27. Maksimovic M, Kovacevic V. Protective and reactivating effects of HI-6-toxogonin mixture in rats and guinea-pigs poisoned by nerve agents. Acta Pharm Jugoslay 1989; 39: 27-33.

28. Marrs TC, Rice P, Vale JA. The role of oximes in the treatment of nerve agent poisoning in civilian casualties. Toxicol Rev 2006; 25: 297-323.

29. Maxwell DM, Koplovitz I, Worek F, Sweeney RE. A structure-activity analysis of the variation in oxime efficacy against nerve agents. Toxicol Appl Pharmacol 2008; 231: 157-64.

30. Musilek K, Holas O, Kuca K et al. Synthesis of monooxime-monocarbamoyl bispyridinium compounds bearing (E)-but-2-ene linker and evaluation of their reactivation activity against tabun- and paraoxon-inhibited acetylcholinesterase. J Enzym Inhib Med Chem 2008; 23: 70-6.

31. Musilek K, Kuca K, Jun D, Dolezal M. Progress in synthesis of new acetylcholinesterase reactivators in period 1990-2004. Curr Org Chem 2007; 11: 229-38.

32. Nurulain SM, Lorke DE, Hasan MY et al. Efficacy of eight experimental bispyridinium oximes against paraoxon-induced mortality: comparison with the conventional oximes pralidoxime and obidoxime. Neurotox Res 2009; 16: 60-7.

33. Ohtomi S, Takase M, Kumagai F. Sarin poisoning in Japan. A clinical experience in Japan Self Defense Force (JSDF) Central Hospital. Int Rev Arm Ser 1996; 69 : $97-102$ 
34. Szinicz L, Worek F, Thiermann H, Kehe K, Eckert S, Eyer P. Development of antidotes: problems and strategies. Toxicology 2007; 233: 23-30.

35. Tallarida R, Murray R. Manual of Pharmacological Calculation with Computer Programs. New York: Springer-Verlag, 1987: 195.

36. Worek F, Aurbek N, Thiermann H. Reactivation of organophosphate-inhibited human AChE by combinations of obidoxime and HI 6 in vitro. J Appl Toxicol 2007; 27: 582-8.

Received: $25 / 08 / 2011$

Accepted in revised form: 05/12/2011

\section{Corresponding author:}

Prof. Jiří Kassa, M.D., CSc., Trebešská 1575, Faculty of Military Health Sciences, 50001 Hradec Kralove, Czech Republic; e-mail: kassa@pmfhk.cz 